Cross-identity moral licensing: Why gender representation in tech may be stifled despite a diversity of qualified applicants

Shoshana N. Jarvis ${ }^{1}$, Soph S. Pashtunyar ${ }^{2}$, Shayna A. Howlett ${ }^{3}$, Rodolfo Mendoza-Denton ${ }^{3}$

1. Haas School of Business, University of California, Berkeley, 2. Department of Psychology, University of California, Los Angeles, 3. Department of Psychology, University of California, Berkeley

Acknowledgments: This work was supported by a grant from the Kapor Center. The first author is supported by a NSF Graduate Research Fellowship DGE 1752814. The authors would like to thank Jordan Leitner for feedback on design, Travis Riddle and Zachary Heinemann for feedback on analyses, Sa-kiera Hudson and Derek Brown for feedback on previous versions of this manuscript, and Charles Xie, Eden Marquez de Leon, and Molly Stern for their assistance. 


\begin{abstract}
Gender and racial diversity in tech is a persistent issue in the United States. Efforts to increase diversity may not be effective due to moral licensing and viewing underrepresented groups interchangeably. Moral licensing has focused on effects within one identity (displays of feminist beliefs leading to sexist actions). We test whether moral licensing can reverberate across identities: cross-identity moral licensing (displays of feminist beliefs leading to racist actions). Study 1, showed no effects of moral licensing on hiring decisions using the original manipulation. In Study 2, hiring managers in the tech sector completed two successive hiring rounds, with the first designed to license the second. White women were negatively impacted by same-identity and cross-identity moral licensing, while there were no effects of moral licensing for Black men. This work provides preliminary evidence that cross-identity moral licensing could help explain why efforts to increase representation fall short for women in tech.
\end{abstract}




\section{Cross-identity moral licensing: Why gender representation in tech may be stifled despite a diversity of qualified applicants}

Gender and racial diversity in tech has been a notable and persistent issue in the United States. Despite making up nearly half of the total workforce, a 2020 analysis by the Bureau of Labor Statistics (2020) reported only a quarter of individuals working in "computer and mathematical" occupations are women. Moreover, this staggeringly low number is a mere $1 \%$ increase in women's representation in the last decade (Bureau of Labor Statistics, 2010). Further, Black and Latinx individuals are among the most underrepresented in technology; together they make up $13 \%$ of the technical workforce despite accounting for $31 \%$ of the total work force (Deleersnyder et al., 2021; Kapor Center, 2020). In fact, one recent metanalysis (Quillian et al., 2017) of field experiments found little to no changes in hiring discrimination for Black and Latinx workers in the past three decades. Although upwards of 8 billion dollars are spent annually on diversity training in tech, the numbers suggest it has had no effect in decreasing bias or increasing diversity (Houser, 2019; Onyeador et al., 2021; Paluck \& Green, 2009).

One potential explanation for why diversity issues persist despite public efforts to create institutional change is that diversity policies provide a shield for companies to continue to act in discriminatory ways (Dover et al., 2014; Monin \& Miller, 2001). Within the context of hiring, this would translate to choosing to hire majority applicants after hiring a minority applicant because the commitment to diversity would have been fulfilled. Because people minoritized by race and gender are often targeted for diversity initiatives, particularly in tech, it could be that minoritized identities may be treated interchangeably. Extending past research on moral licensing, we test if hiring an applicant with one minoritized identity (e.g., a White woman) 
would license participants to not hire minority applicants across domains of identity (e.g., a Black man).

\section{Impact of Diversity Initiatives}

Organizational diversity statements have become hallmarks on webpages for most large companies (Emmott \& Worman, 2008). However, there is limited evidence that diversity initiatives and training sessions in organizations further support or benefit underrepresented people (Dobbin \& Kalev, 2016; Onyeador et al., 2020, 2021). For instance, when presented with disparities in promotions and pay for underrepresented group members or discrimination claims, White men view the disparities and claims as less legitimate when diversity policies are also present (Dover et al., 2014; Kaiser et al., 2013). The existence of the diversity policy legitimizes any existing or future acts of discrimination because the policy is presumed to counteract the influence of bias (Leslie, 2019). Thus, any existing differences are presumed to be earned and deserved. The inclusion of diversity initiatives may be detrimental to the populations they seek to support as employees and decision makers may undermine a company's desire to acknowledge disparities. In the case of hiring, having diversity initiatives could allow employers to prematurely decide diversity aims have been reached.

\section{Moral Licensing}

Moral licensing is a cognitive bias in which one moral or socially desirable decision provides a "license" to engage in questionable or immoral behavior. In other words, for the decision-maker, the impact of the negative effect associated with a subsequent decision is diminished because it is canceled out by the positive impact of the initial decision (Monin \& Miller, 2001; for a review see Blanken et al., 2015). Moral licensing has been studied both as an accrual of good deeds to pay off future immoral deeds (Merritt et al., 2010) and by developing a 
moral reputation to protect one's reputation following future immoral actions (Monin \& Miller, 2001).

Moral licensing has been shown to reduce guilt or feelings of responsibility, which has implications for a variety of behaviors including discrimination, charity donations, environmental friendliness, and hiring processes (Burger et al., 2022; Jordan et al., 2011; Monin \& Miller, 2001). For example, after indicating support for President Obama, participants were more likely to give money to White organizations to the detriment of Black organizations (Effron et al., 2009). In the context of hiring processes, after being given the opportunity to express disagreement with overt sexist statements, men were more likely to later exhibit sexist job beliefs in comparison to men who were given the opportunity to disagree with ambiguous statements about gender roles (Monin \& Miller, 2001). Moral licensing has also been found to be vicariously experienced through other ingroup member's virtuous behavior leading to discriminatory behavior (Kouchaki, 2011). It could be the case that overarching company initiatives, like a diversity hiring search, could work in a similar, vicarious manner, licensing employees to act in a discriminatory manner.

Most research to date has only focused on moral licensing within the same identity (e.g., displays of feminist beliefs leading to sexist actions). It has been suggested that moral licensing could potentially cross domains of identity (e.g., displays of feminist beliefs leading to racist actions), but this, to our knowledge, has yet to be systematically investigated (Miller \& Effron,

\footnotetext{
${ }^{1}$ The moral licensing effect builds on moral credits and/or moral credentials. Moral credits can be thought of as an internal ledger of moral behaviors and virtuous deeds that individuals can then utilize as credits that can pay off future immoral or undesirable actions (Merritt et al., 2010). It is important to acknowledge some prior work that also posits a similar view as the moral credit model: idiosyncrasy credit theory (Hollander, 1958) and the moral balance model (Nisan, 1991). On the other hand, moral credentialing operates off of an individual's reputation of their virtuosity and whether they have obtained moral "credentials" (Monin \& Miller, 2001). To explain further, if an individual feels credentialed they will perceive their unethical or morally questionable behavior as less of a breach of morality than it is in reality.
} 
2010). In this paper we differentiate between these two processes as "same-identity moral licensing" and "cross-identity moral licensing."

\section{Present Studies}

The present investigation builds on previous research on moral licensing by testing not only how moral licensing impacts decisions within the same social identity, but how credentialing one identity could impact behaviors for another identity. That is, for example, would establishing oneself as feminist lead to more racist behaviors? To capitalize on ecological validity, we test the impact of cross-identity moral licensing in hiring in tech in two studies with hiring managers in tech. We focus on the tech industry due to widespread cultural focus on tech and the clear practical implications this focus would provide. Additionally, past work has shown moral licensing effects in positions with stereotypes associated with them. STEM, which is predominantly White and male, fits this parameter (Bernard \& Cooperdock, 2018; Fry et al., 2021).

We hypothesized that hiring managers would be less likely to hire White women and Black men after displaying their egalitarian beliefs (Study 1) or hiring an underrepresented candidate in a previous round (Study 2) both for same-identity moral licensing and cross-identity moral licensing. We report all data exclusions (if any), all manipulations, and all measures in each study. All preregistrations, materials, data, and analysis code are available on the Open Science Framework (https://osf.io/3kr2m/).

\section{Study 1}

In Study 1, participants completed the original moral licensing manipulation from Monin and Miller (2001) in which participants were given the opportunity to disagree with blatantly sexist statements. Next, participants rated applicants for a job advertisement for a fictitious tech 
company. Critically, applicants varied on race and gender makeup. They were either mixed White men and White women (same-identity moral licensing), White men and Black men (crossidentity moral licensing), or all White men (control; preregistration:

https://aspredicted.org/C4Z_TP4).

\section{Methods}

\section{Participants}

Hiring managers in tech fields were recruited via a Qualtrics panel. Preregistered exclusion criteria included: failing 2 of 3 attention checks and spending less than 5 minutes on the survey. After exclusions, 315 managers completed the study (180 men, 133 women, 2 something else; 202 White, 57 Asian, 22 Black, 27 Latinx, 5 Multiracial, 2 something else). On average, participants had 12 years of experience working in tech $(S D=9)$ and 7 years working as a hiring manager $(S D=6)$.

\section{Procedure}

All participants completed a demographic screener to ensure that they were hiring managers in tech before being directed to the experiment. In the first stage of the experiment, participants completed the moral licensing manipulation from Monin \& Miller (2001) in which participants read statements about women and selected if they agreed or disagreed with them. In the moral licensing condition, participants read about "most" women acting in stereotypical ways, whereas in the control condition, participants read about "some" women acting in stereotypical ways. Sample items include, "Most/some women are better off at home taking care of the children," and "Most/some women need a man to protect them." According to Monin \& Miller, disagreeing with the "most" condition should allow participants to display their feminist 
beliefs more clearly because those statements are blatantly sexist. In comparison, believing some women acting stereotypically coveys less about a person's feminist beliefs.

Next, participants read a job advertisement for a fictitious tech company and were told that they would be evaluating resumes of applicants. Participants reviewed five resumes that were designed by a research assistant based on LinkedIn profiles of people in low-level tech positions. They were then reviewed by a hiring manager in tech to check if they seemed realistic and were pre-tested to be of equal experience by a sample of mTurkers (range of average ratings $=3.66-3.98$ on a 5 -point Likert scale; $1=$ Very Inexperienced, $5=$ Very Experienced). Names were randomly paired with resumes and communicated race and gender information about the applicant (Bertrand \& Mullainathan, 2004; Greenwald et al., 1998). Thus, the difference between the resumes was the race and gender of the applicants, and differences observed would be due to demographic differences and not qualifications or applicant quality. In the same-identity moral licensing condition, participants saw resumes from 3 White male applicants and 2 White female applicants. In the cross-identity moral licensing condition, participants saw resumes from 3 White male applicants and 2 Black male applicants. In the control condition, participants saw resumes from 5 White male applicants.

\section{Dependent Variables}

Each resume was rated on the following three questions on 5-point Likert scales: (1) "How qualified do you think this candidate is for this job?" ( $1=$ Very Unqualified, $5=$ Very Qualified), (2) "How good of a fit do you think this candidate is for this job?" (1=Not at All, 5=Very Much), (3) "How likely would you be to hire this candidate?" (1=Not at All, 5=Very Much). These items were highly correlated $(r \mathrm{~s}>.65)$, so they were combined to create one index 
of applicant quality $(a=.88)$. Next, participants ranked the resumes in the order they would prefer to interview them.

\section{Exploratory Moderators}

Participants completed internal and external motivations to control prejudice for race and gender (Plant \& Devine, 1998), system justification (Eliezer et al., 2011), social dominance orientation (Ho et al., 2015), colorblindness and multiculturalism ideologies (Ryan et al., 2007), and an impression management scale (Paulhus \& Reid, 1991). Participants also wrote about how they would describe diversity in the tech industry and reported what percentage of managers at tech companies are men and White (separately). These measures were collected for exploratory purposes and were not analyzed for this manuscript.

\section{Results}

\section{Preliminary Analyses}

Initial analyses on the manipulation showed that participants in the moral licensing condition agreed with fewer of the statements than participants in the control condition $\left(M_{\text {moral }}=6.10, S D_{\text {moral }}=1.50, M_{\text {control }}=7.17, S D_{\text {control }}=1.73, t(307)=5.88, p<.001, d=0.66,95 \% C I\right.$ $[0.44,0.89])$. In total, 72 participants in the moral licensing condition agreed with at least one of the sexist statements. In accordance with the preregistration, we did not exclude any participants in the following analyses based on their engagement with the manipulation. The pattern of results did not differ excluding participants who agreed with any of the sexist statements (https://osf.io/qhjax/).

\section{Analytic Approach}


Hypotheses were tested with cross-classified mixed-effects models predicting the two dependent variables ${ }^{2}$ by the moral licensing condition (effect coded: $-0.5=$ control, $0.5=$ moral licensing), resume demographics during the round of hiring (reference coded with White men as the reference group), and the interaction of condition and resume demographics. Random effects were included for each participant and each resume. The interaction of the moral licensing condition and White women resume demographics tests for evidence of same-identity moral licensing because the interaction demonstrates the gender moral licensing manipulation having a differential impact by White applicants' gender. In comparison, the interaction of the moral licensing condition and Black men resume demographics test for evidence of cross-identity moral licensing because the interaction demonstrates the gender moral licensing manipulation having a differential impact by male applicants' race.

There were several deviations from the pre-analysis plan in our preregistration. We did not include the resume name as a random effect because, on reflection, that would control for our effect in the model. We removed the random effect for each participant in the model testing callback rank because there was no variance within participant as all ranks were fundamentally dependent upon each other ${ }^{3}$. Resume display order was a significant covariate, so it was included in all models (centered) for all subsequent analyses. Removing this covariate did not impact the pattern of results (https://osf.io/wuxq4/).

\section{Applicant Quality}

\footnotetext{
${ }^{2}$ Rank was treated as continuous.

${ }^{3}$ When a participant ranks a group of resumes on quality, there could be some amount of covariance in that each person has their own idiosyncratic rating style. However, when a participant ranks a resume as $1^{\text {st }}$ to call back, that definitionally impacts all other resumes as no other resume can be ranked as $1^{\text {st }}$ thereby eliminating measurable within-person covariance.
} 
There were no observed effects of same-identity moral licensing, $b=0.09, t(1499)=0.73$, $p=.465,95 \% C I[-0.15,0.34]$, or cross-identity moral licensing, $b=0.14, t(1511)=1.06, p=.290$, 95\% CI [-0.12, 0.41] (see Table 1 for full model). Of note, White women's resumes were rated of a higher quality compared to White men's resumes, $b=0.14, t(1497)=2.27, p=.023,95 \% C I$ $[0.02,0.26]$.

\section{Callback Rank}

For callback rank, positions with lower numbers (e.g., $1^{\text {st }}$ ) are called back earlier than later numbers (e.g., $3^{\text {rd }}$ ). Thus, in this analysis, lower numbers are interpreted as a higher priority callback. There was evidence that White women were prioritized for callbacks earlier than White men, $b=-0.30, t(1565)=-2.98, p=.003,95 \% C I[-0.50,-0.10]$. However, there was no effect of same-identity moral licensing, $b=0.17, t(1565)=0.81, p=.417,95 \% C I[-0.23,0.57]$, or crossidentity moral licensing, $b=-0.01, t(1565)=-0.04, p=.966,95 \% C I[-0.44,0.42]$.

\section{Discussion}

In an initial investigation, there was no evidence of cross-identity moral licensing or even same-identity moral licensing. In contrast to similar designs in previous research (Monin \& Miller, 2001), the original manipulation did not elicit moral licensing effects. Of note, the manipulation task is not particularly ecologically valid. That is, it is not common in everyday life for people to have the opportunity to spontaneously disagree with sexist statements and then review application materials.

To test for the possibility of cross-identity moral licensing with a more ecologically valid design, we asked hiring managers to make two successive hiring decisions for a fictitious tech company. In the first round, participants were instructed that the company specifically wanted to hire underrepresented candidates. Round 1 was designed to elicit moral licensing for race or 
gender (or a third control condition): three resumes were substantially better than the other two, and two of the better resumes had either White women's or Black men's names attached to them. Thus, participants could feel positively about their choices as the candidates were the most qualified and fit the instructed diversity criteria. In Round 2, participants evaluated resumes for applicants that were of matched quality and were either mixed White men and White women or White men and Black men to test same and cross-identity moral licensing for both race and gender. This study was preregistered (https://aspredicted.org/SX3_LHZ).

\section{Study 2}

\section{Methods}

\section{Participants}

Hiring managers in tech fields were recruited via a Qualtrics panel. This study used the same exclusion criteria as Study 1. After exclusions, 425 managers completed the study (231 men, 191 women, 3 something else; 269 White, 66 Asian, 38 Black, 35 Latinx, 13 Multiracial, 4 something else). Participants had 12 years of experience working in tech $(S D=9)$ and 12 years working as a hiring manager $(S D=9)$.

\section{Procedure}

All participants completed a demographic screener to ensure that they were hiring managers in tech before being directed to the experiment. Participants read a job advertisement for a fictitious tech company and were told that they would be evaluating resumes of applicants. Participants evaluated resumes for two rounds of applicants.

The first round was designed to induce a sense of moral credentialing by highlighting a focus on diversity in the instructions. Resumes in this round were pretested so that three resumes were rated as more experienced (range of average ratings $=4.00-4.19$ ) than the other two 
$\left(M_{1}=3.21, M_{2}=3.42\right.$; on a 5-point Likert scale). In all three conditions, the least qualified applicants had White male names. In the two moral licensing conditions, the two most qualified applicants were either two White women (gender moral licensing) or two Black men (race moral licensing). The third qualified applicant was a White man to reduce suspicion. In making the choice to select two White men instead of at least one of the underrepresented candidates, the manager would be significantly reducing the quality of their hired talent. In the control condition, all candidates were White men.

Participants were then told that the same company was having a second round of hiring four months later. Participants were then shown a similar set of resumes and the same names as in Study 1, and names were randomly paired with the resumes. In the same-identity moral licensing condition, participants saw resumes from three White men and two White women. In the cross-identity moral licensing condition, participants saw resumes from three White men and two Black men (see Figure 1).

\section{Dependent Variables}

Each resume was rated using the same three items as Study 1. The items were highly correlated $\left(r \mathrm{~S}_{\text {Round } 1}>.72 ; r \mathrm{~S}_{\text {Round2 }}>.80\right)$, so they were combined to create one index of applicant quality $\left(a_{\text {Round1 }}=.91 ; a_{\text {Round2 }}=.93\right)$. Next, participants ranked the resumes in the order they would prefer to interview them.

\section{Exploratory Moderators}

The moderators from Study 1 were also collected for exploratory purposes but not analyzed for this manuscript.

\section{Results}

Preliminary Analyses 
To determine if participants engaged in the moral licensing task, we compared quality scores of the resumes for the three resumes we identified as being of higher quality to that of the lower quality resumes and if the quality scores were moderated by moral licensing condition. As expected, the higher quality resumes were rated as being of higher quality than the lower quality resumes, $b=0.32, t(1699)=8.24, p<.001,95 \% C I[0.24,0.40]$. This effect also held when limiting the higher quality candidates to just the two underrepresented candidates, $b=0.55$, $t(1699)=14.81, p<.001,95 \% C I[0.48,0.62]$. Quality did not significantly differ by condition or the quality level by condition interactions (all $p$ 's $>.12$ ). Thus all participants, on average, saw the higher quality resumes as being of higher quality regardless of condition.

Then, we tested the extent to which participants engaged with the manipulation as expected by comparing if participants ranked at least one of the higher quality underrepresented resumes in their top two by condition using a logistic regression. There were no significant differences in compliance by condition in the paired contrasts (all $p \mathrm{~s}>.07$ ). In total, 87 participants did not include one of the top two higher quality resumes in their top 2 ranks $\left(N_{\text {control }}=21 ; N_{\text {gender }}=36 ; N_{\text {race }}=30\right)$. Non-compliance was not an issue of random responding as even the non-compliant participants rated the top two resumes as stronger than the other three, $b=0.23, t(347)=3.12, p=.002,95 \% C I[0.09,0.38]$. Additionally, the pattern of results did not differ when excluding participants who did not respond as strongly to the manipulation as we expected (https://osf.io/dcwnh/).

\section{Analytic Approach}

The analytic approach mirrored that of Study 1. Hypotheses were tested with crossclassified mixed-effects models predicting the two dependent variables by the moral licensing condition (reference coded with control condition as the reference group), resume demographics 
during the second round of hiring (reference coded with White men as the reference group), and the interaction of condition and resume demographics, controlling for display order (centered). Random effects were included for each participant and each resume. Deviations from the preanalysis plan were also consistent with that of Study 1: (1) resume name was not included as a random effect, and (2) the random effect for each participant was removed from the rank model, and (3) display order remained as a covariate (centered). Removing this covariate did not impact the pattern of results (https://osf.io/z5wyd/).

The interaction of the gender moral licensing condition and White women resume demographics tests for evidence of same-identity moral licensing because the interaction demonstrates the gender moral licensing manipulation having a differential impact by White applicants' gender. The interaction of the race moral licensing condition and Black men resume demographics tests for evidence of same-identity moral licensing because the interaction demonstrates the race moral licensing manipulation having a differential impact by male applicants' race. To test cross-identity moral licensing, we include the interaction of the race moral licensing condition by gender demographics as well as the interaction of the gender moral licensing manipulation by race demographics.

\section{Applicant Quality}

There was no evidence for gender same-identity moral licensing, $b=0.07, t(1891)=0.55$, $p=.583,95 \% C I[-0.17,0.31]$ or race same-identity moral licensing, $b=0.06, t(1868)=0.53$, $p=.600,95 \% C I[-0.17,0.29]$. There was also no evidence for cross-identity moral licensing starting with gender, $b=-0.07, t(1887)=-0.58, p=.559,95 \% C I[-0.31,0.17]$, or starting with race, $b=0.07, t(1907)=0.52, p=.606,95 \% C I[-0.18,0.32]$ (see Table 2 for full model).

\section{Callback Rank}


Consistent with Study 1, there was weak evidence that White women were prioritized to call back earlier than White men, $b=-0.27, t(2112)=-1.93, p=.054,95 \% C I[-0.55,0.00]$. Meanwhile, there was no evidence of Black men as targets experiencing effects of moral licensing. The race moral licensing manipulation did not induce same-identity moral licensing, $b=0.19, t(2112)=1.04, p=.296,95 \% C I[-0.17,0.56]$, nor did Black men fall victim to crossidentity moral licensing, $b=0.24, t(2112)=1.26, p=.208,95 \% C I[-0.13,0.62]$.

However, the moral licensing manipulations in Round 1 proved to be particularly influential for White women. There was evidence of same-identity moral licensing after the gender moral licensing manipulation, $b=0.69, t(2112)=3.58, p<.001,95 \% C I[0.31,1.07]$ (see Figure 2). After examining the simple effects, this effect was driven by White women being listed later on the callback list than White men within the gender moral licensing condition, $b=-$ $0.42, t(2112)=-3.19, p=.004$, and as compared to when they would be called back in the control condition (when no underrepresented candidates could be selected in Round 1), $b=-0.50$, $t(2112)=-3.00, p=.008$.

There was also evidence of cross-identity moral licensing after the race manipulation, $b=0.58, t(2112)=2.91, p=.004,95 \% C I[0.19,0.97]$. Upon reviewing the simple effects contrasts, this effect was driven by White women being listed later on the call-back list after race-based moral licensing than they would be called back in the control condition, $b=-0.43, t(2112)=-2.47$, $p=.036$. Taken together, when participants had the opportunity to select qualified White women or Black men in an initial hiring round, they ranked White women later in the callback list compared to when underrepresented candidates were not available to select in the first round.

\section{Discussion}


In two studies, we tested whether moral licensing on one identity could translate to deprioritizing applicants with a differing stigmatized identity. In Study 1, there was no evidence of effects due to moral licensing using the original (Monin \& Miller, 2001) moral licensing manipulation - either for within one identity or across identities. Using a more realistic paradigm in Study 2, White women were impacted by both same-identity moral licensing and crossidentity moral licensing. Despite rating the resumes similarly regardless of demographics, moral credentialing impacted participants' callback rankings: White women were deprioritized in a hiring round after the opportunity to hire White women or Black men in an earlier round. However, the impacts of moral licensing were not felt equally across identities. There were no observed impacts of moral licensing for Black men either in the same-identity or cross-identity moral licensing conditions. While past work has found perceivers to interpret stigma directed at one social identity to carry over to other social-identities (Chaney \& Sanchez, 2018; Sanchez et al., 2017), here we find some evidence that actors treat social-identities interchangeably.

The observation of effects for White women and not Black men in Study 2 could be driven by how participants ranked the resumes in the control condition. In the control condition, White women were ranked very early, which created room for their rankings to drop. Black men, by contrast, were ranked on average at the midpoint. Even after not having the opportunity to hire for gender/racial diversity in Round 1, they did not seize the opportunity to hire Black men in Round 2 like they did for White women. Because there was no preference for Black men in the control condition, it was hard for their ranking to become worse. It may also be the case that effects were not seen for Black men because the perceived need to increase representation of women in STEM is so great in comparison (Rattan et al., 2019; Williams \& Ceci, 2015). The 
higher focus towards the need for women in STEM within the United States may have made it so participants did not even consider prioritizing Black men in hiring decisions.

An argument could be made that participants in the moral licensing conditions would be acting rationally by not prioritizing White women or Black men in a second round of hiring because a "diverse" candidate was already prioritized in Round 1 . Therefore, even in the crossidentity licensing condition, diversity aims were addressed and would not need to be addressed in Round 2. However, this argument is only logical if diversity is conceptualized as a dichotomy between White men and all other groups. Hiring across multiple identities would then be tautological because adequate diversity effort is satisfied after only one hire. While hiring a Black man increases the racial diversity of a company, it does not improve gender diversity thus not negating the need to hire more women (Brannon et al., 2018).

One of the key strengths of the current research is that it included participants familiar with the experimental task and regularly do as part of their jobs, hiring in STEM, with realistic resumes. Additionally, for Study 2, the manipulation of moral licensing was ecologically valid. That is, the task reflected situations they would likely experience within their jobs. In contrast, the Study 1 manipulation had minimal impacts, if any. It could be the case that twenty years later, expressing feminist beliefs in a questionnaire is not sufficiently powerful to elicit a reactionary response. Alternatively, our participants might not have been feminists or felt particularly strongly about feminist issues, as evidenced by the number of participants who agreed with the sexist statements. For that manipulation to work, it assumes that all participants are feminists. Participants need to both disagree with the sexist statements and feel good about demonstrating their feminist beliefs. Thus, that manipulation might not have been well-suited to elicit moral licensing, whereas the manipulation in Study 2 did not require participants to 
necessarily adhere to feminist or anti-racist ideals. Instead, participants could make a hiring decision that would allow them to feel like a diversity quota had been satisfied enough to not need to hire diverse candidates in a second round of hiring regardless of their beliefs.

The aim of this work was to cleanly test the extent to which moral licensing could transcend social-identities. To accomplish this aim, we limited the identities represented to include only one stigmatized identity. As a result, people who hold multiple stigmatized identities were de facto excluded from the design. Intersectional approaches to identity science are critical because lived experiences can and do differ based on interactions of stigmatized and non-stigmatized identities (Else-Quest \& Hyde, 2016; Purdie-Vaughns \& Eibach, 2008; Shields, 2008). Future research should investigate how people who hold multiple stigmatized identities impacts cross-identity moral licensing effects through processes such as intersectional invisibility (Purdie-Vaughns \& Eibach, 2008) or combinations of privileged and stigmatized identities (Pittinsky et al., 2000).

The present research provides nascent evidence for cross-identity moral licensing, specifically for White women to be less likely to be hired after increasing racial diversity. To the extent that cross-identity moral licensing occurs in business settings, it would inhibit efforts to increase gender and racial representation in business corporations. Cross-identity moral licensing also could help explain why efforts to increase representation fail to be as effective as desirednon-White men are considered to be interchangeable. Future work is necessary to continue to evaluate the extent to which cross-identity moral licensing occurs and impacts consequential decisions. 


\section{References}

Bernard, R. E., \& Cooperdock, E. H. G. (2018). No progress on diversity in 40 years. Nature Geoscience, 11(5), 292-295. https://doi.org/10.1038/s41561-018-0116-6

Bertrand, M., \& Mullainathan, S. (2004). Are Emily and Greg More Employable Than Lakisha and Jamal? A Field Experiment on Labor Market Discrimination. American Economic Review, 94(4), 991-1013. https://doi.org/10.1257/0002828042002561

Blanken, I., van de Ven, N., \& Zeelenberg, M. (2015). A Meta-Analytic Review of Moral Licensing. Personality and Social Psychology Bulletin, 41(4), 540-558. https://doi.org/10.1177/0146167215572134

Brannon, T. N., Carter, E. R., Murdock-Perriera, L. A., \& Higginbotham, G. D. (2018). From Backlash to Inclusion for All: Instituting Diversity Efforts to Maximize Benefits Across Group Lines: From Backlash to Inclusion for All. Social Issues and Policy Review, 12(1), 57-90. https://doi.org/10.1111/sipr.12040

Burger, A. M., Schuler, J., \& Eberling, E. (2022). Guilty pleasures: Moral licensing in climaterelated behavior. Global Environmental Change, 72, 102415. https://doi.org/10.1016/j.gloenvcha.2021.102415

Chaney, K. E., \& Sanchez, D. T. (2018). Gender-Inclusive Bathrooms Signal Fairness Across Identity Dimensions. Social Psychological and Personality Science, 9(2), 245-253. https://doi.org/10.1177/1948550617737601

Deleersnyder, D., Koshy, S., Scott, A., Lynch, D., \& Gangas, L. (2021). Expanding the Latinx tech pipeline: The time for action is now. https://www.kaporcenter.org/wpcontent/uploads/2021/10/KC21008_latin-tech-update_final.pdf

Dobbin, F., \& Kalev, A. (2016, July 1). Why Diversity Programs Fail. Harvard Business Review, 
10. https://hbr.org/2016/07/why-diversity-programs-fail

Dover, T. L., Major, B., \& Kaiser, C. R. (2014). Diversity initiatives, status, and systemjustifying beliefs: When and how diversity efforts de-legitimize discrimination claims. Group Processes \& Intergroup Relations, 17(4), 485-493. https://doi.org/10.1177/1368430213502560

Effron, D. A., Cameron, J. S., \& Monin, B. (2009). Endorsing Obama licenses favoring Whites. Journal of Experimental Social Psychology, 45(3), 590-593. https://doi.org/10.1016/j.jesp.2009.02.001

Eliezer, D., Townsend, S. S. M., Sawyer, P. J., Major, B., \& Mendes, W. B. (2011). SystemJustifying Beliefs Moderate the Relationship Between Perceived Discrimination and Resting Blood Pressure. Social Cognition, 29(3), 303-321. https://doi.org/10.1521/soco.2011.29.3.303

Else-Quest, N. M., \& Hyde, J. S. (2016). Intersectionality in Quantitative Psychological Research: I. Theoretical and Epistemological Issues. Psychology of Women Quarterly, 40(2), 155-170. https://doi.org/10.1177/0361684316629797

Emmott, M., \& Worman, D. (2008). The steady rise of CSR and diversity in the workplace. Strategic HR Review, 7(5), 28-33. https://doi.org/10.1108/14754390810893071

Fry, R., Kennedy, B., \& Funk, C. (2021, April 1). STEM Jobs See Uneven Progress in Increasing Gender, Racial and Ethnic Diversity. Pew Research Center Science \& Society. https://www.pewresearch.org/science/2021/04/01/stem-jobs-see-uneven-progress-inincreasing-gender-racial-and-ethnic-diversity/

Greenwald, A. G., McGhee, D. E., \& Schwartz, J. L. (1998). Measuring individual differences in implicit cognition: The implicit association test. Journal of Personality and Social 
Psychology, 74(6), 1464-1480.

Ho, A., Sidanius, J., Kteily, N., Sheehy-Skeffington, J., Pratto, F., Henkel, K., Foels, R., \& Stewart, A. (2015). The Nature of Social Dominance Orientation: Introducing the Social Dominance Orientation7 Scale. SSRN Electronic Journal. https://doi.org/10.2139/ssrn.2372729

Hollander, E. P. (1958). Conformity, status, and idiosyncrasy credit. Psychological Review, 65(2), 117-127. https://doi.org/10.1037/h0042501

Houser, K. A. (2019). Can AI Solve the Diversity Problem in the Tech Industry: Mitigating Noise and Bias in Employment Decision-Making. Stanford Technology Law Review, 22, 290.

Jordan, J., Mullen, E., \& Murnighan, J. K. (2011). Striving for the Moral Self: The Effects of Recalling Past Moral Actions on Future Moral Behavior. Personality and Social Psychology Bulletin, 37(5), 701-713. https://doi.org/10.1177/0146167211400208

Kaiser, C. R., Major, B., Jurcevic, I., Dover, T. L., Brady, L. M., \& Shapiro, J. R. (2013). Presumed fair: Ironic effects of organizational diversity structures. Journal of Personality and Social Psychology, 104(3), 504-519. https://doi.org/10.1037/a0030838

Kapor Center. (2020). Black technology workforce: Designing a more inclusive future. https://www.kaporcenter.org/wpcontent/uploads/2021/06/Kapor_Center_Black_Tech_Workforce_combined_commentary _infographic_updated.pdf

Kouchaki, M. (2011). Vicarious moral licensing: The influence of others' past moral actions on moral behavior. Journal of Personality and Social Psychology, 101(4), 702-715. https://doi.org/10.1037/a0024552 
Leslie, L. M. (2019). Diversity Initiative Effectiveness: A Typological Theory of Unintended Consequences. Academy of Management Review, 44(3), 538-563. https://doi.org/10.5465/amr.2017.0087

Merritt, A. C., Effron, D. A., \& Monin, B. (2010). Moral Self-Licensing: When Being Good Frees Us to Be Bad. Social and Personality Psychology Compass, 4(5), 344-357. https://doi.org/10.1111/j.1751-9004.2010.00263.x

Monin, B., \& Miller, D. T. (2001a). Moral credentials and the expression of prejudice. Journal of Personality and Social Psychology, 81(1), 33-43. https://doi.org/10.1037/00223514.81 .1 .33

Nisan, M. (1991). The moral balance model: Theory and research extending our understanding of moral choice and deviation. In Handbook of moral behavior and development, Vol. 1: Theory; Vol. 2: Research; Vol. 3: Application (pp. 213-249). Lawrence Erlbaum Associates, Inc.

Onyeador, I. N., Hudson, S. T. J., \& Lewis, N. A. (2021). Moving Beyond Implicit Bias Training: Policy Insights for Increasing Organizational Diversity. Policy Insights from the Behavioral and Brain Sciences, 8(1), 19-26. https://doi.org/10.1177/2372732220983840

Onyeador, I. N., Wittlin, N. M., Burke, S. E., Dovidio, J. F., Perry, S. P., Hardeman, R. R., Dyrbye, L. N., Herrin, J., Phelan, S. M., \& van Ryn, M. (2020). The Value of Interracial Contact for Reducing Anti-Black Bias Among Non-Black Physicians: A Cognitive Habits and Growth Evaluation (CHANGE) Study Report. Psychological Science, 31(1), 18-30. https://doi.org/10.1177/0956797619879139

Paluck, E. L., \& Green, D. P. (2009). Prejudice Reduction: What Works? A Review and 
Assessment of Research and Practice. Annual Review of Psychology, 60(1), 339-367. https://doi.org/10.1146/annurev.psych.60.110707.163607

Paulhus, D., \& Reid, D. (1991). Enhancement and Denial in Socially Desirable Responding. Journal of Personality and Social Psychology, 60, 307-317. https://doi.org/10.1037/0022-3514.60.2.307

Pittinsky, T. L., Shih, M., \& Ambady, N. (2000). Will a Category Cue Affect You? Category Cues, Positive Stereotypes and Reviewer Recall for Applicants. Social Psychology of Education, 4(1), 53-65. https://doi.org/10.1023/A:1009656413789

Plant, E. A., \& Devine, P. G. (1998). Internal and external motivation to respond without prejudice. Journal of Personality and Social Psychology, 75(3), 811-832. https://doi.org/10.1037/0022-3514.75.3.811

Purdie-Vaughns, V., \& Eibach, R. P. (2008). Intersectional Invisibility: The Distinctive Advantages and Disadvantages of Multiple Subordinate-Group Identities. Sex Roles, 59(5), 377-391. https://doi.org/10.1007/s11199-008-9424-4

Quillian, L., Pager, D., Hexel, O., \& Midtbøen, A. H. (2017). Meta-analysis of field experiments shows no change in racial discrimination in hiring over time. Proceedings of the National Academy of Sciences, 114(41), 10870-10875. https://doi.org/10.1073/pnas.1706255114

Rattan, A., Steele, J., \& Ambady, N. (2019). Identical applicant but different outcomes: The impact of gender versus race salience in hiring. Group Processes \& Intergroup Relations, 22(1), 80-97. https://doi.org/10.1177/1368430217722035

Ryan, C. S., Hunt, J. S., Weible, J. A., Peterson, C. R., \& Casas, J. F. (2007). Multicultural and Colorblind Ideology, Stereotypes, and Ethnocentrism among Black and White Americans. Group Processes \& Intergroup Relations, 10(4), 617-637. 
https://doi.org/10.1177/1368430207084105

Sanchez, D. T., Chaney, K. E., Manuel, S. K., Wilton, L. S., \& Remedios, J. D. (2017). Stigma by Prejudice Transfer: Racism Threatens White Women and Sexism Threatens Men of Color. Psychological Science, 28(4), 445-461. https://doi.org/10.1177/0956797616686218

Shields, S. A. (2008). Gender: An Intersectionality Perspective. Sex Roles, 59(5), 301-311. https://doi.org/10.1007/s11199-008-9501-8

Williams, W. M., \& Ceci, S. J. (2015). National hiring experiments reveal 2:1 faculty preference for women on STEM tenure track. Proceedings of the National Academy of Sciences, 112(17), 5360-5365. https://doi.org/10.1073/pnas.1418878112 
Table 1. Effects of gender moral licensing manipulation and resume demographics on assessments of resume quality and callback rank for Study 1.

Quality

\begin{tabular}{lccccc}
\hline & & & & \multicolumn{2}{c}{$95 \%$ CI } \\
& $b$ & $t(d f)$ & $p$ & lower & upper \\
\hline Intercept & 3.76 & $45.73(5)$ & $<.001$ & 3.58 & 3.93 \\
Gender Moral Licensing & -0.12 & $-1.59(391)$ & .113 & -0.26 & 0.03 \\
White Woman Resume & 0.14 & $2.27(1497)$ & .023 & 0.02 & 0.26 \\
Black Men Resume & 0.04 & $0.63(1510)$ & .529 & -0.09 & 0.17 \\
Display Order & -0.05 & $-3.29(1253)$ & .001 & -0.07 & -0.02 \\
Gender Moral Licensing X White Women Resume & 0.09 & $0.73(1499)$ & .465 & -0.15 & 0.34 \\
Gender Moral Licensing X Black Men Resume & 0.14 & $1.06(1511)$ & .290 & -0.12 & 0.41 \\
\hline
\end{tabular}

Rank

\begin{tabular}{lccccc}
\hline & & & & \multicolumn{2}{c}{$95 \%$ CI } \\
& $b$ & $t(d f)$ & $p$ & lower & upper \\
\hline Intercept & 3.05 & $25.85(4)$ & $<.001$ & 2.80 & 3.30 \\
Gender Moral Licensing & -0.01 & $-0.16(1564)$ & .873 & -0.17 & 0.15 \\
White Woman Resume & -0.30 & $-2.98(1565)$ & .003 & -0.50 & -0.10 \\
Black Men Resume & -0.07 & $-0.61(1565)$ & .542 & -0.28 & 0.15 \\
Display Order & 0.08 & $3.18(1565)$ & .002 & 0.03 & 0.13 \\
Gender Moral Licensing X White Women Resume & 0.17 & $0.81(1565)$ & .417 & -0.23 & 0.57 \\
Gender Moral Licensing X Black Men Resume & -0.01 & $-0.04(1565)$ & .966 & -0.44 & 0.42 \\
\hline
\end{tabular}


Figure 1. Diagram of procedure and conditions in Study 2. The dark dashed arrows display same-identity moral licensing conditions. The dark solid arrows display cross-identity moral licensing conditions. The light dashed arrows display the control conditions with no moral licensing.

Round 1: Moral Licensing

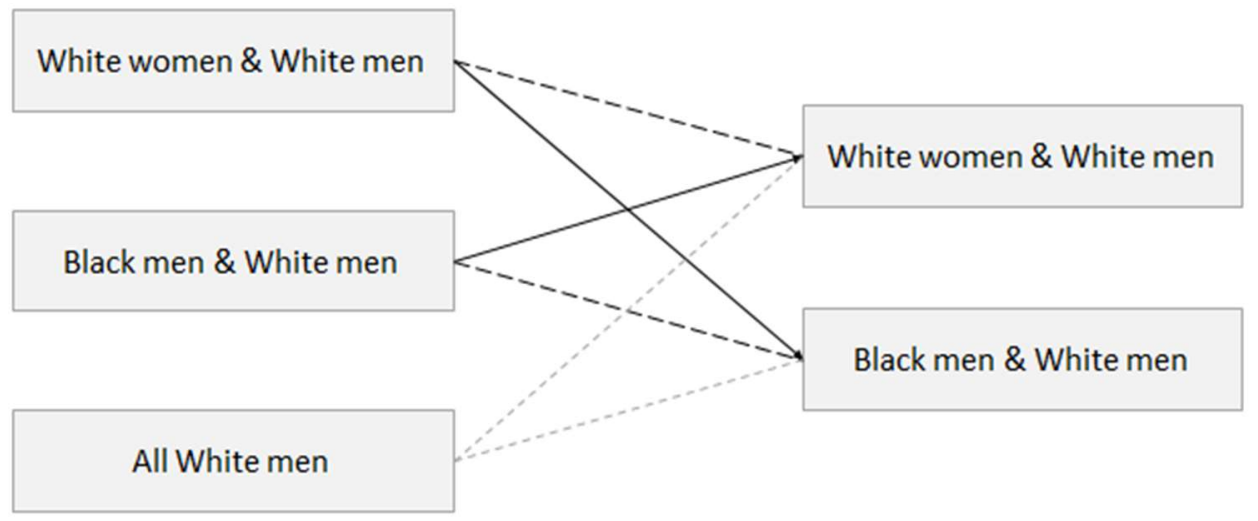


Figure 2. Ranks of all surveys by demographics of the resumes and moral licensing condition during the first hiring round. Each small dot represents an individual resume rating. Large black dots are means surrounded by $95 \%$ confidence intervals.

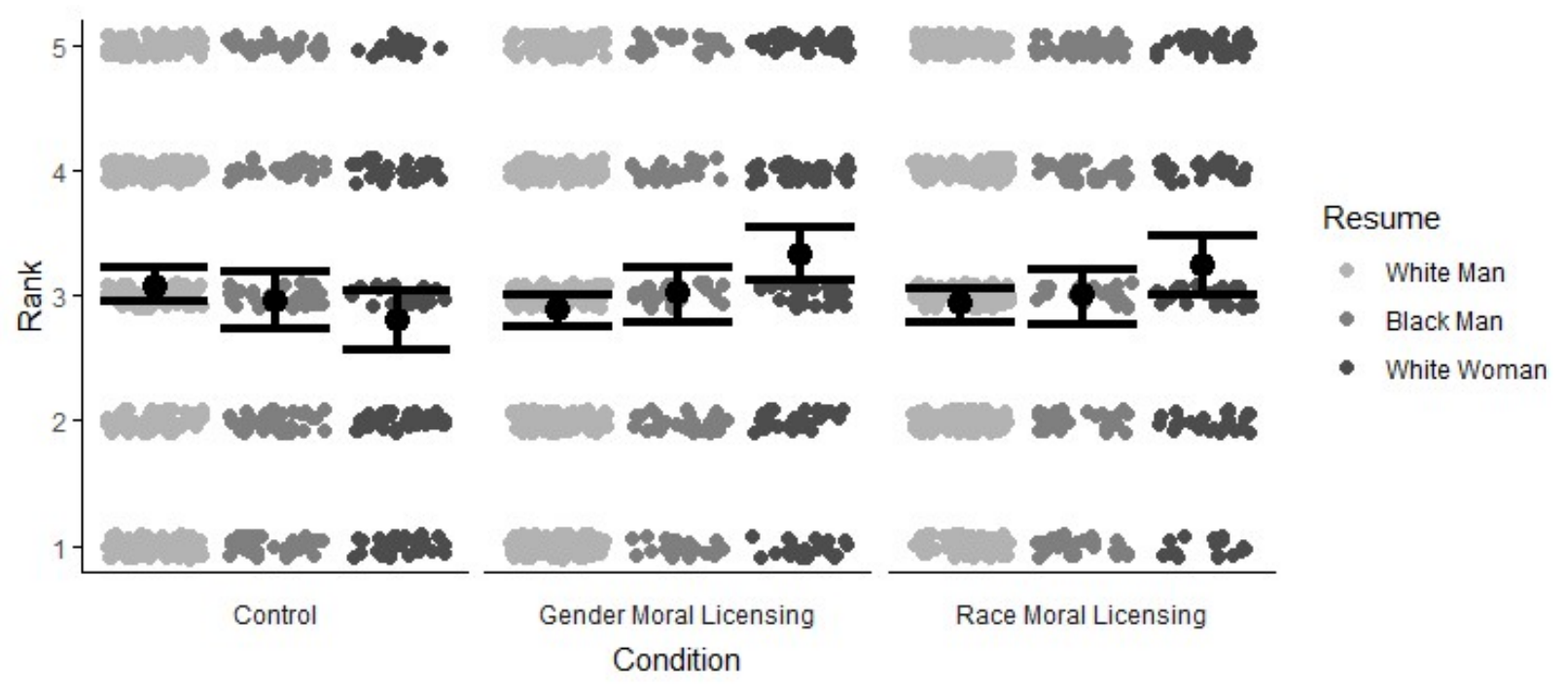


Table 2. Effects of gender and race moral licensing manipulations and resume demographics on assessments of resume quality and callback rank for Study 2 .

Quality

\begin{tabular}{lccccc}
\hline & & & & \multicolumn{2}{c}{$95 \%$ CI } \\
& $b$ & $t(d f)$ & $p$ & lower & upper \\
\hline Intercept & 3.59 & $40.15(18)$ & $<.001$ & 3.42 & 3.77 \\
Gender Moral Licensing & -0.09 & $-0.92(560)$ & .358 & -0.28 & 0.10 \\
Race Moral Licensing & -0.04 & $-0.40(560)$ & .690 & -0.23 & 0.15 \\
White Woman Resume & -0.07 & $-0.81(1908)$ & .418 & -0.25 & 0.10 \\
Black Men Resume & 0.08 & $0.98(1865)$ & .327 & -0.08 & 0.24 \\
Display Order & 0.00 & $0.07(1686)$ & .948 & -0.02 & 0.03 \\
Gender Moral Licensing X White Women Resume & 0.07 & $0.55(1891)$ & .583 & -0.17 & 0.31 \\
Race Moral Licensing X Black Men Resume & 0.06 & $0.53(1868)$ & .600 & -0.17 & 0.29 \\
Gender Moral Licensing X Black Men Resume & -0.07 & $-0.58(1887)$ & .559 & -0.31 & 0.17 \\
Race Moral Licensing X White Women Resume & 0.07 & $0.52(1907)$ & .606 & -0.18 & 0.32 \\
\hline
\end{tabular}

Rank

\begin{tabular}{lccccc}
\hline & \multicolumn{1}{c}{ 95\% CI } \\
& $b$ & $t(d f)$ & $p$ & lower & upper \\
\hline Intercept & 3.07 & $27.97(8)$ & $<.001$ & 2.85 & 3.30 \\
Gender Moral Licensing & -0.19 & $-1.97(2112)$ & .049 & -0.38 & 0.00 \\
Race Moral Licensing & -0.15 & $-1.54(2112)$ & .124 & -0.34 & 0.04 \\
White Woman Resume & -0.27 & $-1.93(2112)$ & .054 & -0.55 & 0.00 \\
Black Men Resume & -0.12 & $-0.89(2111)$ & .374 & -0.37 & 0.14 \\
Display Order & 0.01 & $0.27(2112)$ & .786 & -0.04 & 0.05 \\
Gender Moral Licensing X White Women Resume & 0.69 & $3.58(2112)$ & $<.001$ & 0.31 & 1.07 \\
Race Moral Licensing X Black Men Resume & 0.19 & $1.04(2112)$ & .296 & -0.17 & 0.56 \\
Gender Moral Licensing X Black Men Resume & 0.24 & $1.26(2112)$ & .208 & -0.13 & 0.62 \\
Race Moral Licensing X White Women Resume & 0.58 & $2.91(2112)$ & .004 & 0.19 & 0.97 \\
\hline
\end{tabular}

